\title{
A lifestyle medicine model for family medical practices based on 9-years of clinical data including food, weight, glucose, carbs/sugar, and walking using linear elastic glucose theory and GH-Method: math- physical medicine, Part I4 (No. 367)
}

\begin{abstract}
This article is aimed at assisting family medical practices for obesity and type 2 diabetes (T2D) control using the lifestyle medicine model, which is also the Part 14 of his recently developed linear elastic glucose theory (LEGT).

More than 33 million Americans, about 1 in 10, have diabetes, and approximately $90 \%$ to $95 \%$ of them have type 2 diabetes (T2D), where $86 \%$ also have problems with being overweight or obese. In other words, $7.7 \%$ to $8.2 \%$ of the US population or 25 to 27 million Americans have issues with weight, T2D conditions and multiple complications.

The author is a patient who suffered with being overweight/obesity and T2D for over 25 years. He faced many complications from 2002 to 2010. Over the past 11 years, he dedicated himself to research diabetes and its complications. In this article, he describes the simple and straightforward yet highly precise method to control his chronic disease conditions, including weight and glucose. The results of his research provide proof through a big data analytics of his collected input data through the continuous research and implementation efforts during the past 9 years. His findings have finally achieved satisfactory health results with high mathematical precision on his various biomarker predictions.
\end{abstract}

He named this the "lifestyle medicine" approach. The purpose of writing this article is to offer a simple but practical approach to patients with chronic diseases like him self.

In summary, the author describes his straightforward implementation model in the following four steps:

1. By reducing his weight from $189 \mathrm{lb}$. to $170 \mathrm{lb}$. $(-19 \mathrm{lb}$. or $-10 \%$ in total weight), cutting off about $50 \%$ of his original over-eating food portion size (from $130 \%$ in 2012 down to $66 \%$ in 2020 , which is $-7 \%$ of his annual food portion reduction from original amount, or $-6 \%$ averaged annual reduction continuously). This food portion reduction will automatically reduce the intake amount of fat and carbohydrates. Although he strictly controls his sugar, and sodium amounts, he maintains a sufficient intake amount of high-quality protein.

2. When his weight dropped from $189 \mathrm{lbs}$. to $170 \mathrm{lbs}$. $(-10 \%$ or $-1.1 \%$ per year), his FPG then decreased from $140 \mathrm{mg} / \mathrm{dL}$ to $102 \mathrm{mg} / \mathrm{dL}(-38 \mathrm{mg} /$ dL or $-27 \%$, or $-3 \%$ per year) accordingly. Weight and FPG are highly correlated $(93 \%)$.

\section{Introduction}

This article is aimed at assisting family medical practices for obesity and type 2 diabetes (T2D) control using the lifestyle medicine model, which is also the Part 14 of his recently developed linear elastic glucose theory (LEGT).

More than 33 million Americans, about 1 in 10, have diabetes, and approximately $90 \%$ to $95 \%$ of them have type 2 diabetes (T2D),
Volume 5 Issue 6 - 2020

\section{Gerald C Hsu}

Medical Research Scientist, eclaireMD Foundation, USA

Correspondence: Gerald C Hsu, Medical Research Scientist, eclaireMD Foundation, USA, Email g.hsu@eclairemd.com

Received: December 05, 2020 | Published: December 28 2020

3. When his FPG dropped, his PPG also reduced from $128 \mathrm{mg} / \mathrm{dL}$ to 108 $\mathrm{mg} / \mathrm{dL}(-20 \mathrm{mg} / \mathrm{dL}$ or $-16 \%$, or $-1.7 \%$ per year), providing he limits his carb/sugar intake amount below 15 grams per meal and walking at least 30 minutes after each meal. He also increased his post-meal walking from 500 steps to 4,400 steps ( +433 post-meal steps per year or $+87 \%$ per year in comparison with his walking steps in 2012).

4. He wants to re-emphasize the importance of diet and exercise. Normally, reduction on food and meal portion will automatically assist on limiting the carbs/sugar intake amount. However, patients should always watch out for the overall nutritional balance. For the author, his carbs/sugar intake amount has been cut down from 20 grams to 12.5 grams per meal ( -7.5 grams or $-38 \%$, or $-4 \%$ per year) as a result of his food portion reduction from $130 \%$ to $66 \%$ (-64\% of food portion or $-7 \%$ per year).

This article merely provides a clinical proof using a quantitative and precision approach. These mathematical and biomedical accomplishments are based on careful physical phenomena observations and related biomedical interpretation and proof process. This particular research project of food nutrition and biomedicine has utilized his developed GH-Method: math-physical medicine in which 366 medical papers have been published. The above four statements are simple to understand; therefore, there is no need to learn fancy theories, complex formulas or equations. No need to take special seminars or attend college courses, take high dosages of medications or supplements, or go through any unnecessary surgeries. There are straight-line relationships existing among food, exercise, weight, and glucose that follow a simple and straight-line route from food portion control to weight reduction and arrive at glucose stability for both FPG and PPG.

where $86 \%$ also have problems with being overweight or obese. In other words, $7.7 \%$ to $8.2 \%$ of the US population or 25 to 27 million Americans have issues with weight, T2D conditions and multiple complications.

The author is a patient who suffered with being overweight/obesity and T2D for over 25 years. He faced many complications from 2002 to 2010. Over the past 11 years, he dedicated himself to research diabetes and its complications. In this article, he describes the simple 
and straight forward yet highly precise method to control his chronic disease conditions, including weight and glucose. The results of his research provide proof through a big data analytics of his collected input data through the continuous research and implementation efforts during the past 9 years. His findings have finally achieved satisfactory health results with high mathematical precision on his various biomarker predictions.

He named this the "lifestyle medicine" approach. The purpose of writing this article is to offer a simple but practical approach to patients with chronic diseases like him self.

\section{Methods}

\section{Background}

To learn more about the author's GH-Method: math-physical medicine (MPM) methodology, readers can refer to his article to understand his developed MPM analysis method in Reference.

\section{Case description}

The author has had T2D for over 25-years, while being obese and overweight. In 2010, his weight was 220 lbs. (BMI 32.5), with a daily average glucose over $200 \mathrm{mg} / \mathrm{dL}$. He has also suffered many diabetes complications, including five cardiac episodes, severe kidney complications, foot ulcer, diabetic retinopathy, bladder infections, hypothyroidism, and others. After receiving warnings from three individual physicians regarding his serious conditions and death threats, he decided to self-study those chronic diseases and tried to make a serious change on his overall lifestyle.

After 9 years of his continuous efforts, over the past 6 months in 2020, his average weight is $169.5 \mathrm{lbs}$. (BMI 24.9) and his average daily glucose is $103 \mathrm{mg} / \mathrm{dL}$ (FPG 94, PPG 106) without taking any medications or insulin injections.

\section{Data collection}

Since $1 / 1 / 2012$, the author developed a research-oriented software on his iPhone to collect all of his diabetes-related medical data and lifestyle details. He also spend the entire year of 2014 to develop a mathematical model of metabolism which has been served as the cornerstone of his follow-up research work. He started to keep a complete daily record of his weight (morning and bedtime) since $4 / 11 / 2015$, and his glucoses since $6 / 1 / 2015$. Prior to mid-2015, he had sparse data that were not as complete compared to the period after mid-2015.

In addition, he started to collect his glucose data using a continuous glucose monitor (CGM) sensor device from 5/5/2018. He has accumulated approximately 91 glucose data per day with 13 glucose data per meal over a 3-hour time span. However, he discovered that his average sensor-collected glucoses is about $16 \%$ higher than his finger-pierced glucoses, where his postprandial plasma glucose (PPG) data are measured at 2-hours after the first bite of meal. They are usually located at the lowest position on his 3-hour long sensor PPG waveforms.

In order to keep the data consistency and data integrity of his analysis, he decided to use finger glucose values in this particular study since it covers a long time period of 9-years.

\section{Mathematics of data processing}

In this article, he mainly used average annual values from timeseries domain and then conducted correlation coefficient calculations, in addition to pattern and trend analysis via observations of movingaverage waveforms.

Other than utilizing the two GH-modules based on his recently developed linear elastic glucose theory (LEGT) to verify the existing relationships among weight, PPG, FPG, Carbs/sugar intake amount and post-meal walking k-steps, there are no other elaborate mathematical tools used in this analysis and article.

\section{Factors affect body weight}

There are many factors that can affect body weight. Some of these key factors are:
a. Age
b. Gender

Frequency and number of fasting

c. Dietary fat vs. burning of body fat

d. Exercise persistence

e. Stress situations

f. Sleep quality

g. Calories influence on hormones

h. Existing health conditions

i. Thyroid conditions

j. Insulin resistance

\section{k. Metabolic rate}

Weight reduction or control is a complex issue and task. To benefit most patients, the author will skip the detailed academic discussions regarding above-mentioned weight influential factors and concentrate on the discovery and identification of a simpler and more straightforward route to accomplish the goal of weight control.

\section{Results}

Figure 1 shows three curves of weight, FPG, and PPG during the period of 2012 to 2020. Figure 2 depicts three curves of Food portion, Carbs/Sugar intake, and Post-meal Walking during the period of 2012 to 2020. In these two diagrams, all of the 5 curves trend downward year after year, except for the exercise curve of post-meal walking steps that trends upward.

Figures 3-5 reveal correlation coefficients (R) of two curves in a pair since $\mathrm{R}$ can only be calculated between two curves (two sets of data). These three diagrams reflect a total of 9 pairs of results for $\mathrm{R}$ with a total of 6 variables: weight, FPG, PPG, food portion percentage, carbs/sugar amount, and post-meal walking k-steps. In statistics, any $\mathrm{R}$ greater than $50 \%$ means these two variables are closely inter-related with each other. Therefore, from these 9 sets of R percentages, only PPG vs. carbs/sugar has 53\% R and weight vs. PPG has $65 \%(53 \%$ and $65 \%$ are already high enough), all other $\mathrm{R}$ values are greater than $70 \%$. This proves that the 6 variables in this article are highly correlated with one another. 


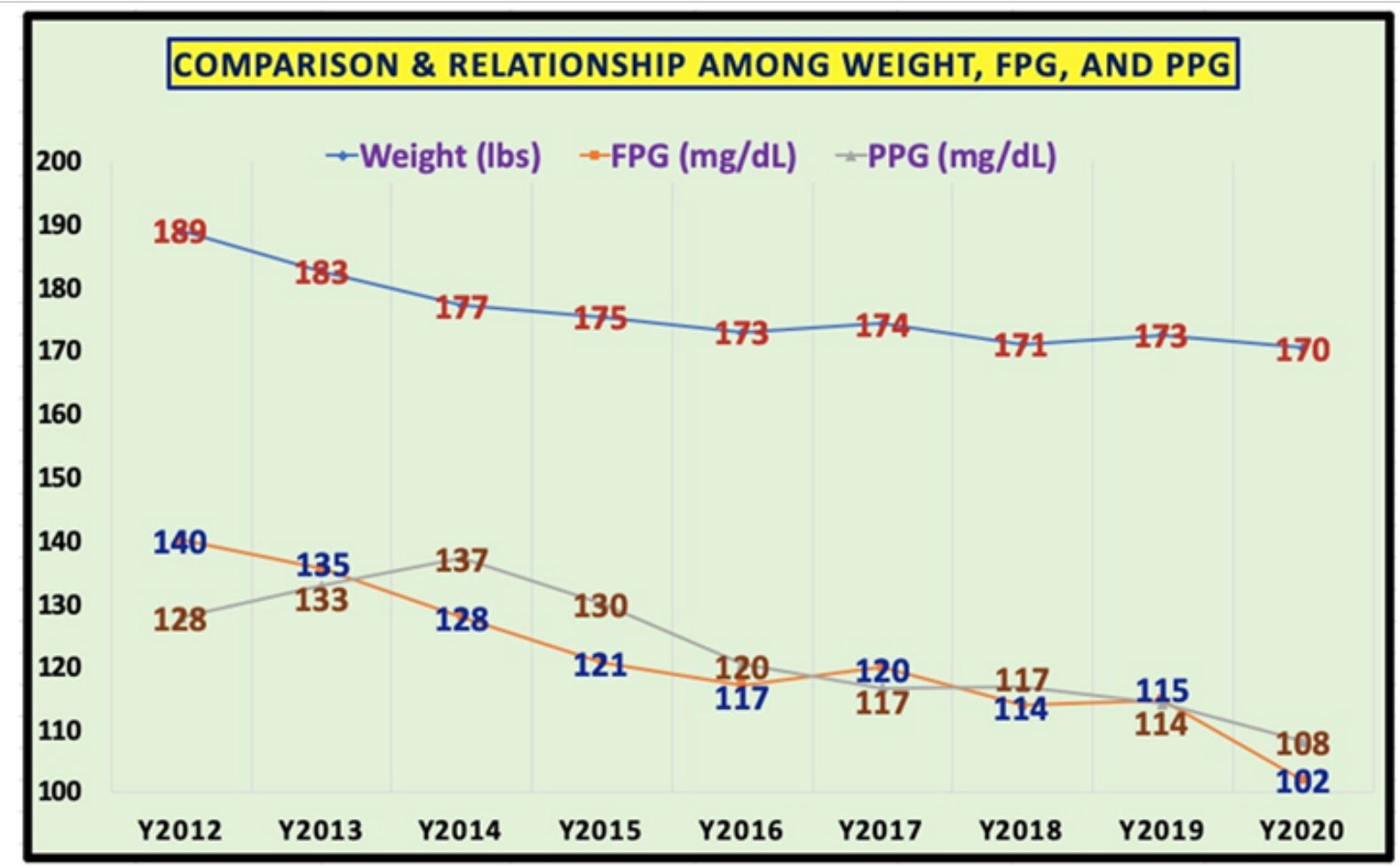

Figure I Comparison among Weight, FPG, and PPG.

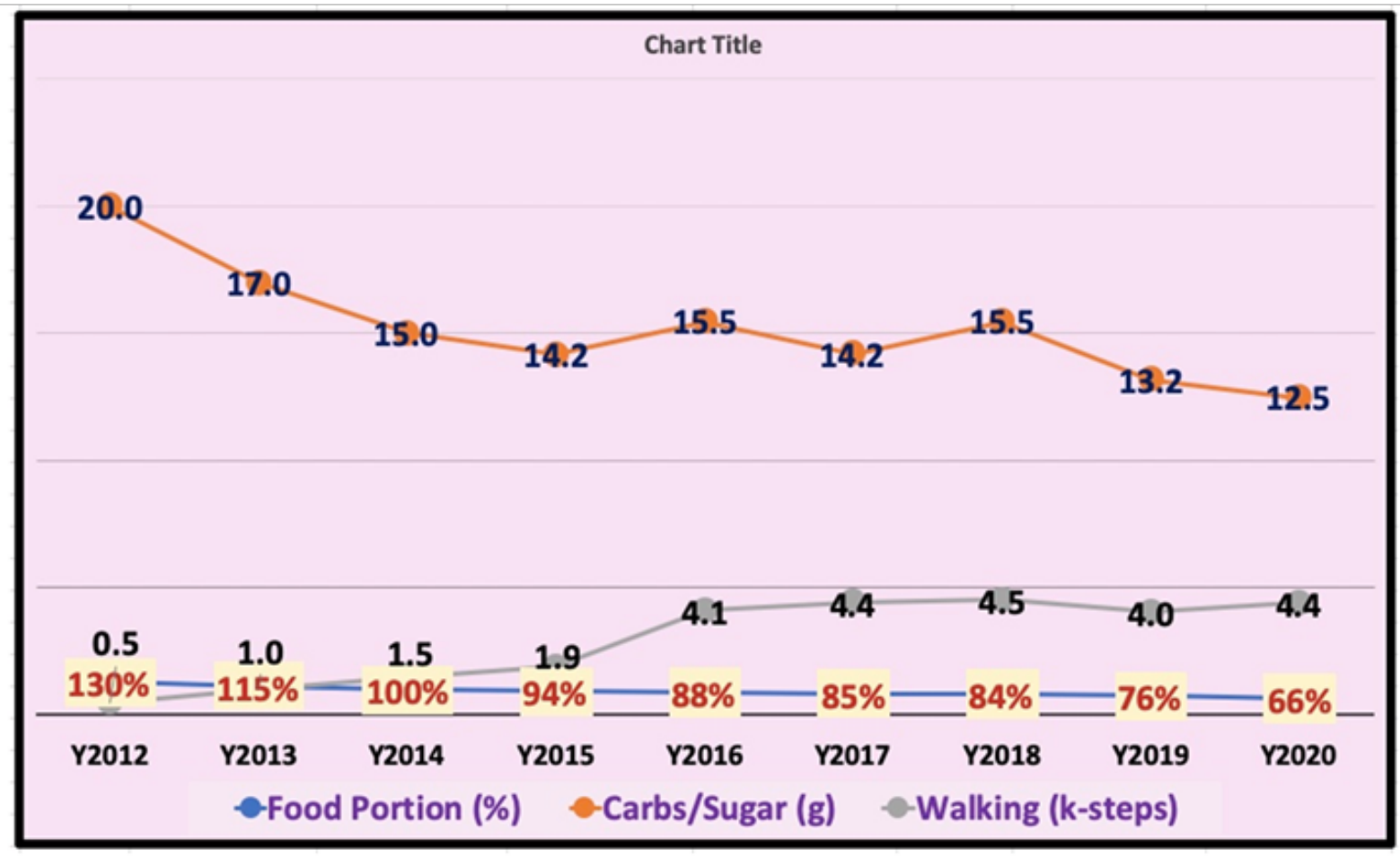

Figure 2 Comparison among Food portion, Carbs/Sugar intake, and Post-meal Walking. 


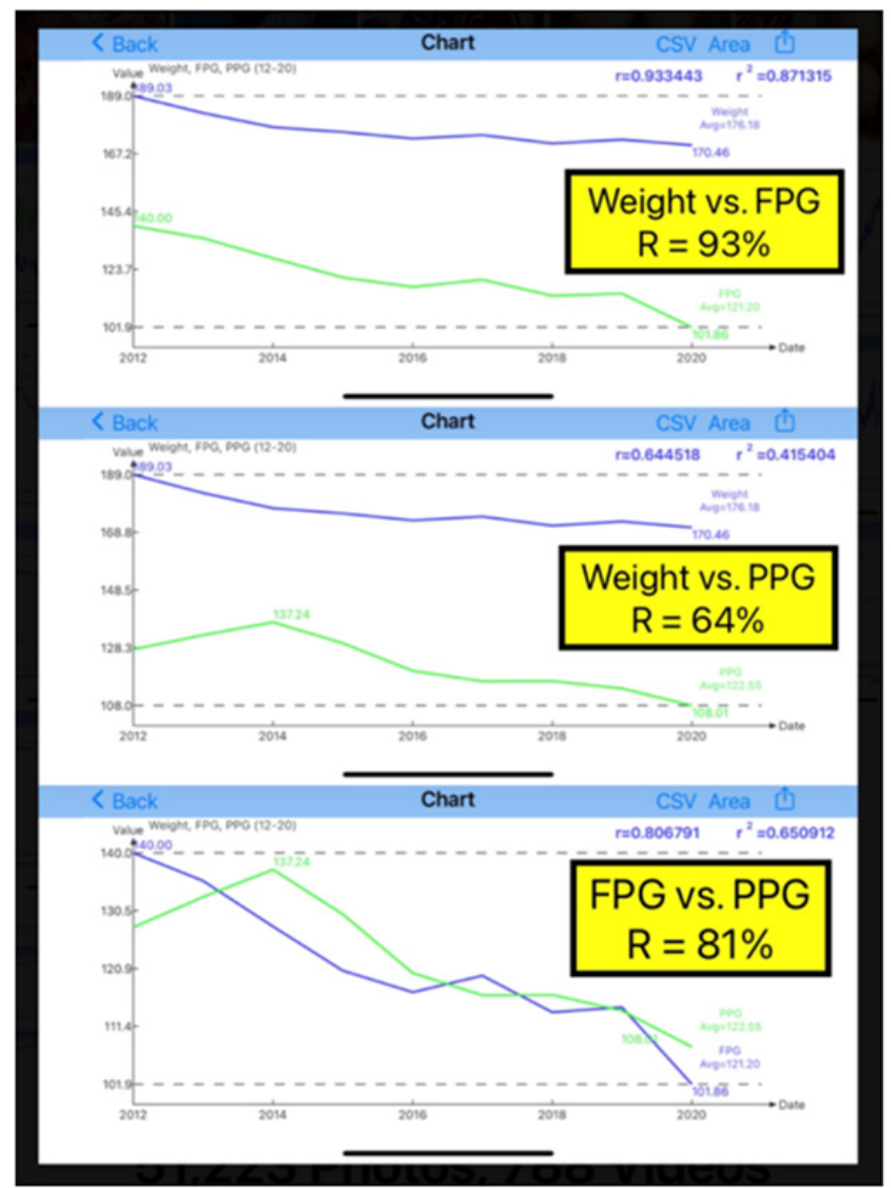

Figure 3 Three correlation coefficients (R) among Weight, FPG, and PPG.

Figure 6 summarizes 9 correlation coefficients into one table. By observing this table, readers will have a clear picture regarding the "tight relationships" among weight, glucoses (both FPG and PPG), food portion percentage, Carbs/sugar intake amount, and post-meal walking steps.

Figure 7 recaps the annual reduction rates of weight, food portion, FPG, PPG, and carbs/sugar amount.

Finally, Figure 8 displays all of the numerical numbers for data used in this analysis and report.

Figure 9 shows the two calculated GH-modulus values based on LEGT. Here are the definitions of the two GH-modulus:

\section{GH.f-modulus $=$ FPG $/$ Weight}

Predicted PPG $=$ * 5).

$(0.97 * \mathrm{FPG})+($ carbs/sugar * GH.p-modulus $)-($ walking k-steps

Due to his incomplete collected data for both health and lifestyle from 2012-2015, his calculation of GH.p only starts from 2015. There are two key observations of the following conclusive phenomena.

First, GH.f-modulus is continuously moving downward, from 0.74 in 2012 to 0.60 in 2020 which means that his health conditions of being overweight and diabetes are getting better year after year. Second, his GH.p-modulus values are between 1.6 and 2.5 which are expected values based on his prior research. The special and highest GH.p-modulus value of 2.5 in 2020 is due to his excellent control on low carbs/sugar intake and glucose values resulting from no travel and routine lifestyle during the 2020 COVID-19 quarantine period.

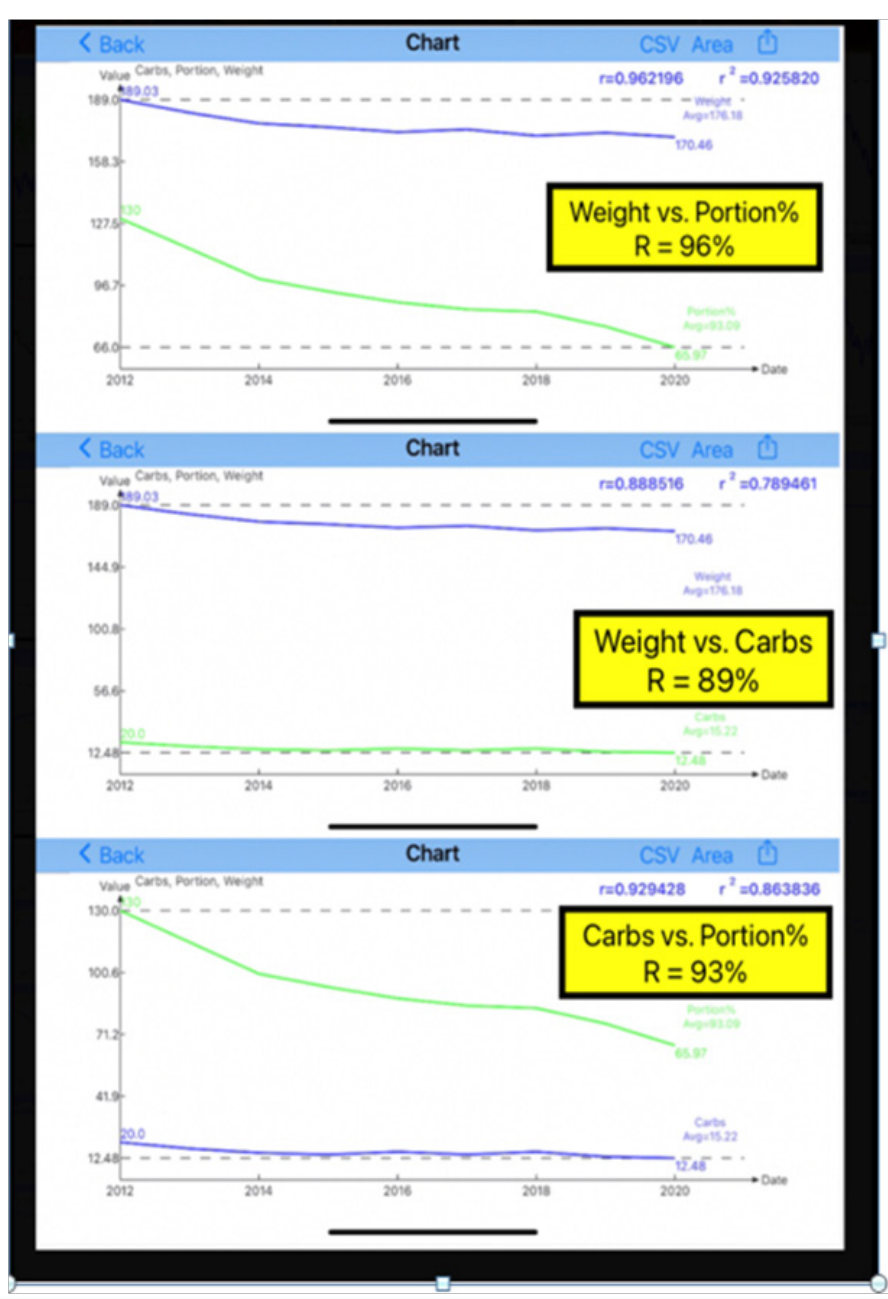

Figure 4 Three correlation (R) among Weight, Food portion, and Carbs/Sugar.

The following table lists the reduction amount of each key variable from 2012 to 2020. They are listed in a form of 2012 amount, 2020 amount, change amount. The only exceptional variable is the postmeal walking k-steps which is an "increased" amount.
Weight:
$(189,170,-19)$
FPG:
PPG:

Food portion: $(130 \%, 66 \%,-64 \%)$

Carbs/Sugar: $(20.0,12.48,-7.52)$

Walking steps: $(0.5,4.404,+\mathbf{3 . 9 0 4})$

In other words, for his case, he has reduced $\sim 50 \%$ of his annual average meal portion from $130 \%$ to $66 \%$ with a $19 \mathrm{lb}$. reduction in his weight (-10\%), then his FPG would be decreased by $38 \mathrm{mg} / \mathrm{dL}(-27 \%)$ 
and his PPG would be reduced by $20 \mathrm{mg} / \mathrm{dL}(-16 \%)$. This proves the existence of a "straight-line route"from food portion control to weight and glucose control

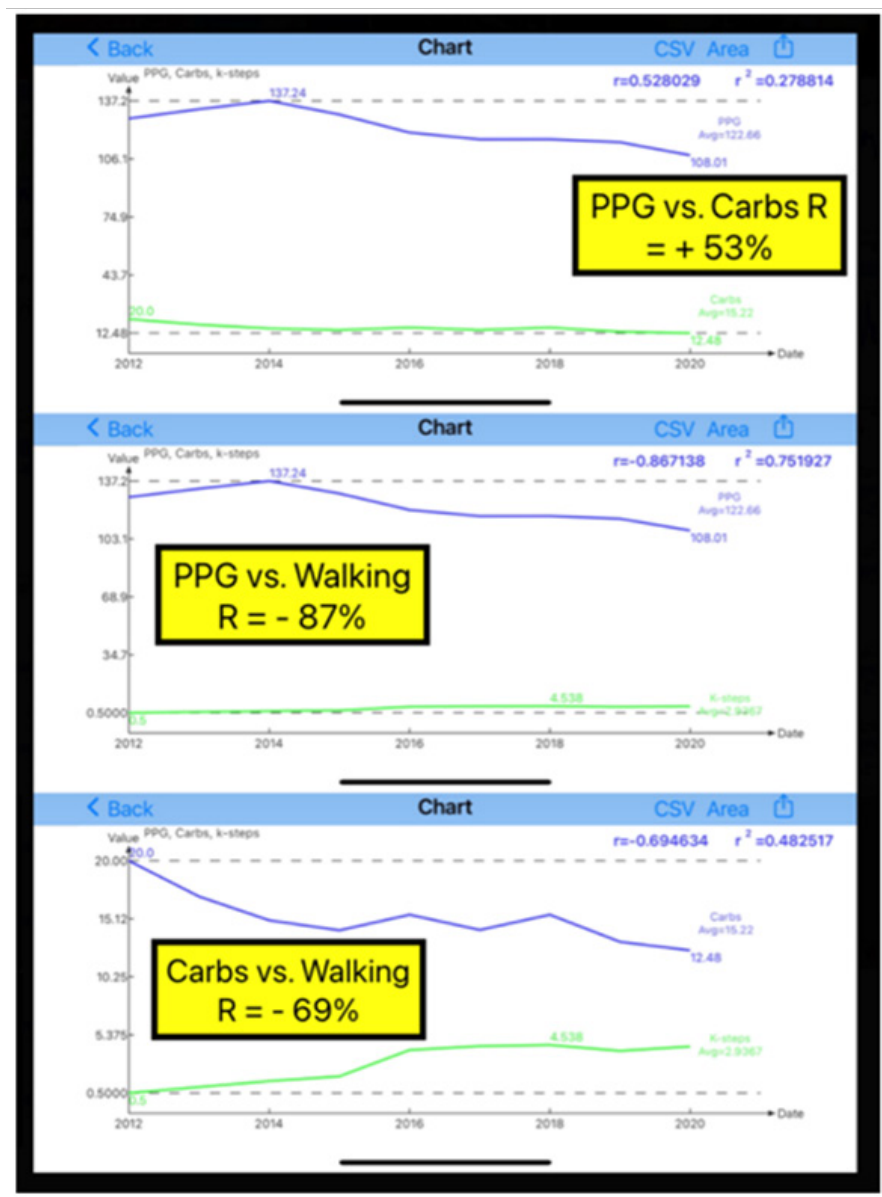

Figure 5 Three correlation coefficients (R) among PPG, Carbs/Sugar, and Post-meal walking.

Most T2D patients, who do not possess sufficient knowledge of food nutrition and have bad habits of overeating, their intake of carbohydrates, sugar, proteins, and fat would exceed the recommended amounts. As a result, this would cause problems with controlling both their weight and glucose. Of course, theoretically, when you get too much input energy via food, you must burn off the energy through physical activities and exercise. Unfortunately, most T2D patients are senior citizens. Generally speaking, most of them have a sedentary lifestyle; therefore, their choice and level of activity of exercise are generally limited. So, the author's advice to elderly diabetes patients is to focus on "post-meal walking". They just need to walk with a normal speed for approximately 30 minutes after each meal, which should be sufficient enough for them. In this way, they will easily achieve their target of walking 10,000 steps per day by burning off $\sim 400$ calories per day.

The best food choice is limiting the amount of carbs/sugar and sodium with very minimal fat and having sufficient high-quality proteins and vitamins. If $\mathrm{T} 2 \mathrm{D}$ patients pay attention to their food and meal portion along with carbs/sugar intake amount, combined with exercise as mentioned above, then their weight and glucose will simultaneously improve..$^{2-6}$

\section{Correlation Coefficient (R) between Biomarkers}

\begin{tabular}{|c|c|c|}
\hline Weight vs. FPG & Weight vs. PPG & FPG vs. PPG \\
\hline $93.34 \%$ & $64.45 \%$ & $80.68 \%$ \\
\hline Weight vs. Food & Weight vs. Carbs & Food vs. Carbs \\
\hline $\mathbf{9 6 . 2 2} \%$ & $\mathbf{8 8 . 8 5} \%$ & $92.94 \%$ \\
\hline PPG vs. Carbs & PPG vs. Walking & Carbs vs. Walking \\
\hline $\mathbf{+ 5 2 . 8 0 \%}$ & $-86.71 \%$ & $-69.46 \%$ \\
\hline & & $\Theta$ eclaireMD \\
\hline
\end{tabular}

Figure 6 Summary table of 9 correlation coefficients.

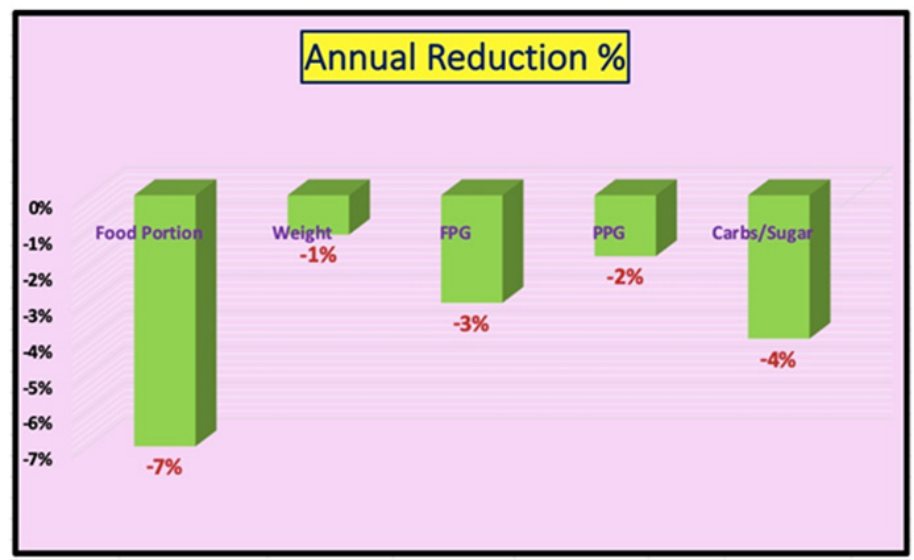

Figure 7 Annual reduction rates.

\section{Conclusion}

1. In summary, the author describes his straightforward implementation model in the following four steps: By reducing his weight from $189 \mathrm{lb}$. to $170 \mathrm{lb}$. (-19 lb. or $-10 \%$ in total weight), cutting off about $50 \%$ of his original overeating food portion size (from $130 \%$ in 2012 down to $66 \%$ in 2020 , which is $-7 \%$ of his annual food portion reduction from original amount, or $-6 \%$ average annual reduction continuously). This food portion reduction will automatically reduce the intake amount of fat and carbohydrates. Although he strictly controls his sugar, and sodium amounts, he maintains a sufficient intake amount of high-quality protein.

2. When his weight dropped from $189 \mathrm{lbs}$. to $170 \mathrm{lbs}$. $(-10 \%$ or $-1.1 \%$ per year), his FPG then decreased from $140 \mathrm{mg} / \mathrm{dL}$ to 102 $\mathrm{mg} / \mathrm{dL}(-38 \mathrm{mg} / \mathrm{dL}$ or $-27 \%$, or $-3 \%$ per year) accordingly. Weight and FPG are highly correlated (93\%).

3. When his FPG dropped, his PPG also reduced from $128 \mathrm{mg} / \mathrm{dL}$ to $108 \mathrm{mg} / \mathrm{dL}$ (-20 mg/dL or $-16 \%$, or $-1.7 \%$ per year), providing he limits his carb/sugar intake amount below 15 grams per meal and walking at least 30 minutes after each meal. He also increased his 
post-meal walking from 500 steps to 4,400 steps ( +433 post-meal steps per year or $+87 \%$ per year in comparison with his walking steps in 2012).

4. He wants to re-emphasize the importance of diet and exercise Normally, reduction on food and meal portion will automatically assist on limiting the carbs/sugar intake amount. However, patients should always watch for the overall nutritional balance. For the author, his carbs/sugar intake amount has been cut down from 20 grams to 12.5 grams per meal (-7.5 grams or $-38 \%$, or $-4 \%$ per year) as a result of his food portion reduction from $130 \%$ to $66 \%$ ( $-64 \%$ of food portion or $-7 \%$ per year).

\begin{tabular}{|c|c|c|c|c|}
\hline $1 / 1 / 12$ & Height (inches) & & & \\
\hline \multirow[t]{2}{*}{$11 / 22 / 20$} & 69.5 & & & \\
\hline & Weight (Ibs) & FPG (mg/dL) & PPG (mg/dL) & BMI \\
\hline Y2012 & 189 & 140 & 128 & 27.5 \\
\hline Y2013 & 183 & 135 & 133 & 26.6 \\
\hline Y2014 & 177 & 128 & 137 & 25.8 \\
\hline Y2015 & 175 & 121 & 130 & 25.5 \\
\hline Y2016 & 173 & 117 & 120 & 25.2 \\
\hline Y2017 & 174 & 120 & 117 & 25.4 \\
\hline Y2018 & 171 & 114 & 117 & 24.9 \\
\hline Y2019 & 173 & 115 & 114 & 25.1 \\
\hline \multirow[t]{2}{*}{ Y2020 } & 170 & 102 & 108 & 24.8 \\
\hline & Food Portion (\%) & Carbs/Sugar (g) & Walking (k-steps) & Glucose $(\mathrm{mg} / \mathrm{dL})$ \\
\hline Y2012 & $130 \%$ & 20.0 & 0.5 & 131 \\
\hline Y2013 & $115 \%$ & 17.0 & 1.0 & 133 \\
\hline Y2014 & $100 \%$ & 15.0 & 1.5 & 135 \\
\hline Y2015 & $94 \%$ & 14.2 & 1.9 & 128 \\
\hline Y2016 & $88 \%$ & 15.5 & 4.1 & 119 \\
\hline Y2017 & $85 \%$ & 14.2 & 4.4 & 117 \\
\hline Y2018 & $84 \%$ & 15.5 & 4.5 & 116 \\
\hline Y2019 & $76 \%$ & 13.2 & 4.0 & 114 \\
\hline Y2020 & $66 \%$ & 12.5 & 4.4 & 106 \\
\hline
\end{tabular}

Figure 8 Data table.

This article merely provides a clinical proof using a quantitative and precision approach. These mathematical and biomedical accomplishments are based on careful physical phenomena observations and related biomedical interpretation and proof process This particular research project of food nutrition and biomedicine has utilized his developed GH-Method: math-physical medicine in which 366 medical papers have been published. The above four statements are simple to understand; therefore, there is no need to learn fancy theories, complex formulas or equations. No need to take special seminars or attend college courses, take high dosages of medications or supplements, or go through any unnecessary surgeries. There are straight-line relationships existing among food, exercise, weight, and glucose that follow a simple and straight-line route from food portion control to weight reduction and arrive at glucose stability for both FPG and PPG. 


\begin{tabular}{|c|c|c|c|}
\hline & GH.f-modulus & GH.p-modulus & Predicted PPG \\
\hline Y2012 & 0.74 & & \\
\hline Y2013 & 0.74 & & \\
\hline Y2014 & 0.72 & & \\
\hline Y2015 & 0.69 & 1.6 & 130 \\
\hline Y2016 & 0.68 & 1.8 & 120 \\
\hline Y2017 & 0.69 & 1.6 & 117 \\
\hline Y2018 & 0.66 & 1.9 & 117 \\
\hline Y2019 & 0.66 & 1.8 & 114 \\
\hline Y2020 & 0.60 & 2.5 & 108 \\
\hline Y2012 & \multicolumn{3}{|c|}{ GH.f \& GH.p Modulus } \\
\hline Y2013 & \multirow{5}{*}{\multicolumn{3}{|c|}{$0.740 .0740 .720 .69-0.68-0.69-0.66-0.66-0.60$}} \\
\hline Y2014 & & & \\
\hline Y2015 & & & \\
\hline Y2016 & & & \\
\hline Y2017 & & & \\
\hline Y2018 & \multirow{3}{*}{\multicolumn{3}{|c|}{ 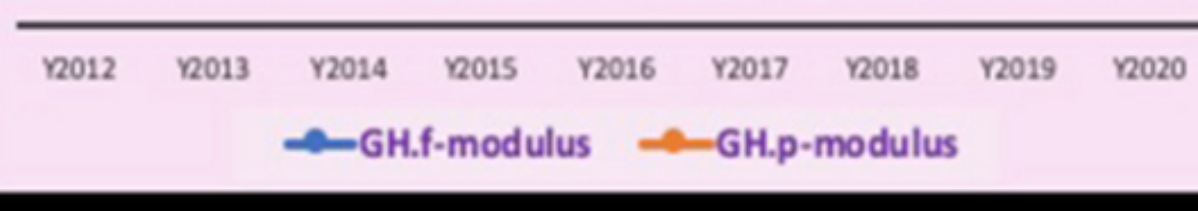 }} \\
\hline Y2019 & & & \\
\hline Y2020 & & & \\
\hline
\end{tabular}

Figure 9 Linear elastic glucose (GH.f-modulus \&GH.p-modulus).

\section{Acknowledgments}

First and foremost, the author wishes to express his sincere appreciation to a very important person in his life, Professor Norman Jones at MIT and University of Liverpool. Not only did he give him the opportunity to study for his PhD at MIT, but he also trained him extensively on how to solve difficult problems and conduct any basic scientific research with a big vision, pure heart, and integrity.

The author would also like to thank Professor James Andrews at the University of Iowa. He helped and supported him tremendously when he first came to the United States. He believed in him and prepared him to build his solid engineering and computer science foundation. $\mathrm{He}$ is forever grateful to his mentor, who has a kind heart and guided him during his undergraduate and master's degree work at Iowa.

\section{Conflicts of interest}

The authors declare have no conflict of interest about the publication of this paper.

\section{References}

1. Hsu, Gerald C. Biomedical research methodology based on GH-Method: math-physical medicine. eclaireMD Foundation, USA, No. 310. 
2. Hsu, Gerald C. Investigating the relationship between annualized weight and annualized food portion percentage along with a segmentation analysis on lowering weight less than 170 pounds using GH-Method: math-physical medicine. eclaireMD Foundation, USA No. 328.

3. Hsu, Gerald C. Investigating the influential factors on body weight and its impact on glucoses using GH-Method: math-physical medicine. eclaireMD Foundation, USA, No. 327

4. Hsu, Gerald C. Behavior psychology and body weight reduction of a T2D patient using GH-Method: math-physical medicine or mentalitypersonality modeling. eclaireMD Foundation, USA, No. 308
5. Hsu, Gerald C. Weight control trend analysis and progressive behavior modification of a T2D patient using GH-Method: math-physical medicine. eclaireMD Foundation, USA, No. 307.

6. Hsu, Gerald C. From weight management via diabetes control to cardiovascular risk reduction. eclaireMD Foundation, USA, No. 27. 